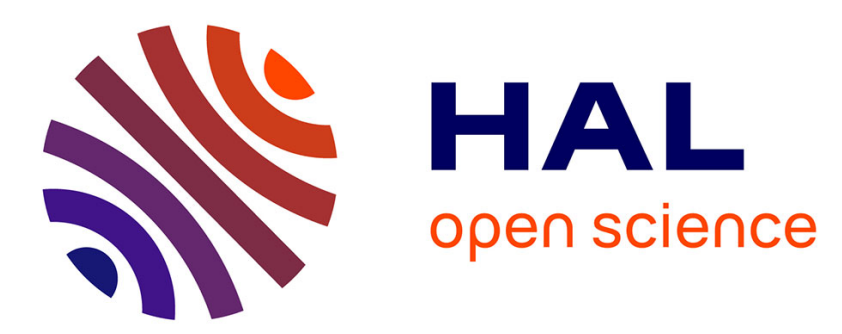

\title{
Bisphosphonates affect migration ability \& cell viability of HUVEC, fibroblasts and osteoblasts in-vitro
}

Christian Walter, Andreas Pabst, Thomas Ziebart, Marcus Oliver Klein, B Al-Nawas

\section{- To cite this version:}

Christian Walter, Andreas Pabst, Thomas Ziebart, Marcus Oliver Klein, B Al-Nawas. Bisphosphonates affect migration ability \& cell viability of HUVEC, fibroblasts and osteoblasts in-vitro. Oral Diseases, 2010, 17 (2), pp.194. 10.1111/j.1601-0825.2010.01720.x . hal-00599899

\section{HAL Id: hal-00599899 https://hal.science/hal-00599899}

Submitted on 11 Jun 2011

HAL is a multi-disciplinary open access archive for the deposit and dissemination of scientific research documents, whether they are published or not. The documents may come from teaching and research institutions in France or abroad, or from public or private research centers.
L'archive ouverte pluridisciplinaire HAL, est destinée au dépôt et à la diffusion de documents scientifiques de niveau recherche, publiés ou non, émanant des établissements d'enseignement et de recherche français ou étrangers, des laboratoires publics ou privés. 


\section{ORALIDISEASES}

\section{Bisphosphonates affect migration ability \& cell viability of HUVEC, fibroblasts and osteoblasts in-vitro}

\begin{tabular}{|c|c|}
\hline Journal: & Oral Diseases \\
\hline Manuscript ID: & ODI-12-09-OM-1484.R2 \\
\hline Manuscript Type: & Original Manuscript \\
\hline $\begin{array}{r}\text { Date Submitted by the } \\
\text { Author: }\end{array}$ & 08-Mar-2010 \\
\hline Complete List of Authors: & $\begin{array}{l}\text { Walter, Christian; University Medical Center of the Johannes } \\
\text { Gutenberg University Mainz, Oral- and Maxillofacial Surgery } \\
\text { Pabst, Andreas; University Medical Center of the Johannes } \\
\text { Gutenberg University Mainz, Oral- and Maxillofacial Surgery } \\
\text { Ziebart, Thomas; University Medical Center of the Johannes } \\
\text { Gutenberg University Mainz, Oral- and Maxillofacial Surgery } \\
\text { Klein, Marcus; University Medical Center of the Johannes Gutenberg } \\
\text { University Mainz, Oral- and Maxillofacial Surgery } \\
\text { Al-Nawas, B; University Mainz, Oral and Maxillofacial Surgery }\end{array}$ \\
\hline Keywords: & $\begin{array}{l}\text { bisphosphonate, bisphosphonate associated osteonecrosis of the } \\
\text { jaws, HUVEC, fibroblast, osteoblast, osteogenic cells }\end{array}$ \\
\hline
\end{tabular}


1

2

3

4

5

6

7

8

9

\section{Bisphosphonates affect migration ability \& cell viability of HUVEC, fibroblasts and osteoblasts in-vitro}

Walter C, Pabst A, Ziebart T, Klein MO, Al-Nawas B

Walter C. and Pabst A. contributed equally

Department of Oral- and Maxillofacial Surgery, plastic surgery; Johannes-GutenbergUniversity Mainz, Germany (Head: Prof. Dr. Dr. W. Wagner)

Correspondence:

Dr. Dr. Christian Walter

Department of Oral and Maxillofacial Surgery

Johannes Gutenberg-University Mainz

Augustusplatz 2

55131 Mainz

Germany

Phone: $\quad$ 0049-(0)-6131-17 3050

Fax: 0049-(0)-6131-176602

Email: $\quad$ walter@mkg.klinik.uni-mainz.de

Running title: Bisphosphonate-associated-osteonecrosis of the jaw

Key words: bisphosphonate, bisphosphonate-associated-osteonecrosis, HUVEC, fibroblast, osteoblast, osteogenic cells

Date of submission: 15.12 .2009

Conflict of interest: no funding was received for this study 


\begin{abstract}
Objective: Bisphosphonate-associated-osteonecrosis of the jaw (BP-ONJ) is a side effect in patients being treated with bisphosphonates. The bisphosphonates most often associated with BP-ONJ are the highly potent nitrogen-containing bisphosphonates e.g. pamidronate or zoledronate. In terms of BP-ONJ aetiology, several theories are being discussed: inhibition of bone remodelling, effect on soft tissues, and antiangiogenic effect of bisphosphonates. The aim of this in-vitro study was to investigate the effect of different potent bisphosphonates on osteoblasts, fibroblasts and human umbilicord vein endothelial cells (HUVEC).

Materials and Methods: Three nitrogen-containing bisphosphonates (ibandronate, pamidronate and zoledronate) and one non-nitrogen-containing bisphosphonate (clodronate) were compared concerning their potency on apoptosis induction (tunel), cell viability (calcein assay) and migration potency (boyden chamber) on osteoblasts, fibroblasts and HUVEC.

Results: The nitrogen-containing bisphosphonates, particularly pamidronate and zoledronate, affect cell viability, cell migration and the induction of apoptosis of osteoblasts, fibroblasts and HUVEC.

Conclusions: These results support the theory that BP-ONJ is a multifactorially caused disease because several cell lines of the oral cavity which are responsible for integrity and wound healing are negatively affected by nitrogen-containing bisphosphonates. Perioperative interruption of bisphosphonate application during dental surgical procedures - if possible might be feasible to promote better wound healing.
\end{abstract}




\section{Introduction}

For over 30 years, bisphosphonates have been used in medicine (Bassett et al., 1969). They are separated into highly potent nitrogen-containing and low potent non-nitrogen-containing bisphosphonates. Through inhibition of osteoclasts, bisphosphonates prevent skeletal related events such as pathological fractures or hypercalcaemic episodes. Their positive effects are without controversy and increase the quality of life in these patients (Ruggiero et al., 2009). The negative side effects can be separated into four major groups: acute-phase reactions, gastrointestinal effects, renal side effects and bisphosphonate associated osteonecrosis of the jaw (BP-ONJ) (Diel et al., 2007). The American Association of Oral and Maxillofacial Surgeons defines BP-ONJ as exposed bone in the maxillofacial region that has persisted for more than eight weeks in combination with a current or previous bisphosphonate therapy, and a lack of head and neck radiation in patient's history (Ruggiero et al., 2009). The frequency of BP-PNJ is higher in patients with malignancies and intravenously delivered, highly potent bisphosphonates such as pamidronate and zoledronate, and lower in patients receiving oral bisphosphonates due to osteoporosis (Ruggiero et al., 2009). Only a few cases of BP-ONJ have been reported in connection with the administration of non-nitrogen containing bisphosphonates such as clodroante (Montazeri et al., 2007).

Several theories on BP-ONJ development are being discussed in the literature (Allen and Burr, 2009). The most common theory concentrates on the impact of bisphosphonates on bone, especially on osteoclasts. Osteoclasts are the main cellular target of bisphosphonates, inhibiting enzymes of the mevalonate pathways (nitrogen containing bisphosphonates) or synthesizing ATP derivates (non nitrogen containing bisphosphonates) (Frith et al., 1997, Rogers et al., 2000). In addition to osteoclasts, osteocytes (Allen and Burr, 2008) and osteoblasts (Walter et al., 2009) are influenced by bisphosphonates. The consequence is suppressed bone remodelling with microdamage to the bone (Mashiba et al., 2005). The fact that, with only one exception (Polizzotto et al., 2006), BP-ONJ appears almost exclusively in 
the jaws still remains unclear. A possible reason is the higher remodelling rate of the jaw, particularly at the alveolar ridge, resulting in higher accumulation of bisphosphonate in comparison to other sites of the skeleton (Allen and Burr, 2009). In addition to bone, some authors focus on the soft tissues in the aetiology of BP-ONJ, since adequate wound healing is lacking in these patients (Reid et al., 2007). Failed wound healing might result in exposed and secondary necrotic bone. A similar mechanism could be discussed in patients with periodontal disease, where the soft tissues are disturbed by inflammation, and no appropriate soft tissue layer covering the bone is present (Walter et al., 2008). It is difficult to explain cases of BP$\mathrm{ONJ}$ at the mylohyoid ridge which lack a trigger factor without taking the impact on the soft tissues into account. Bisphosphonates might be released from the underlying bone and may compromise the very thin mucosal layer in this area. The pressure of the tongue against this ridge, and the influence of the mylohyoid muscle might affect the compromised soft tissue layers so that a defect in the covering soft tissue evolves. Next to the oral keratinocytes (Landesberg et al., 2008, Rubegni and Fimiani, 2006), fibroblasts and blood vessel cells are involved in this process (Walter et al., 2009). The reduced potency of the latter is desired in terms of suppressed angiogenesis tumor therapy (Green and Clezardin, 2002). For some bisphosphonates, a proapoptotic effect on cancer cells is reported (Santini et al., 2003). Therefore bisphosphonates might inhibit several cell types necessary for wound healing, such as osteoblasts, fibroblasts and vessel cells. In summary, a broad range of cells and their functions is affected by bisphosphonates, and not just osteoclasts. Since BP-ONJ frequencies differ among the several bisphosphonates, the impact on cell viability, cell migration and apoptosis of osteoblasts, fibroblasts and endothelial cells was analyzed. 
Materials and Methods

Cell culture: Cell cultures were prepared and maintained according to standard cell culture procedures. Commercially available human umbilicord vein endothelial cells (HUVEC; Lonza, Basel, Switzerland) were cultured in an endothelial basal medium (EBM) supplemented with $1 \mu \mathrm{g} / \mathrm{ml}$ hydrocortisone, $12 \mu \mathrm{g} / \mathrm{ml}$ bovine brain extract, $50 \mu \mathrm{g} / \mathrm{ml}$ gentamicin, $50 \mathrm{ng} / \mathrm{ml}$ amphotericin-B, $10 \mathrm{ng} / \mathrm{ml}$ epidermal growth factor and $10 \%$ fetal calf serum (FCS).

Human osteogenic cells (HOB; Promocell, Heidelberg, Germany), were cultivated in a solution composed of Dulbecco's Modified Eagle's Medium (DMEM) with 1\% PSN, 1\% Lglutamin and $10 \%$ FCS. Before the experiments, the osteogenic cells were positively characterized by immunhistochemical expression of alkaline phosphatase and osteocalcin (labelled streptavidin-botin/horseradish peroxidase).

Fibroblasts (Lonza, Basel, Switzerland) were grown in Stroma Cell Growth Medium (SCGM) with $1 \%$ Penicillin-Streptomycin-Neomycin antibiotic mixture (PSN), 10\% FCS, and 500ng basic fibroblast growth factor per $500 \mathrm{ml}$ medium.

All cell cultures were incubated and cultured in an incubator with $5 \% \mathrm{CO}_{2}$ and $95 \%$ air at $37^{\circ}$ C till the third passage of cell generation. Cells were passaged at regular intervals depending on their growth characteristics using 25\% trypsin (Seromed Biochrom, Berlin, Germany). Calcein viability assay: To analyze the effect of bisphosphonates on cell viability, we evaluated a Calcein Viability Assay. HUVEC, fibroblasts and human osteoblasts were cultivated in standard cell culture as described. All cells were incubated in standard 24-well culture plates with different bisphosphonates (clodronat, ibandronate, pamidronate, zoledronate $)$ in gradient concentrations $(0 \mu \mathrm{mol}, 5 \mu \mathrm{mol}, 50 \mu \mathrm{mol}, 100 \mu \mathrm{mol}, 200 \mu \mathrm{mol}, 500$ $\mu \mathrm{mol})$ for 72 hours. This range of concentrations was selected because in-vivo concentrations in plasma shortly after zoledronate infusion are about $5 \mu \mathrm{mol}$, and concentrations in bone shortly after infusion can be 100 fold higher (Chen et al., 2002). After removing the used 
culture medium from the wells, they were filled with $500 \mu 1$ fresh culture medium and $7 \mu 1$ Calcein-AM (invitrogen ${ }^{\mathrm{TM}}$, Eugene, Oregon, USA) per well. The plates were incubated in a dark cell incubator for 1 hour. Subsequently, the Calcein-AM medium was also removed and cells were detached with $500 \mu 1$ Trypsin-EDTA solution per well. $200 \mu 1$ of the cell- Trypsin solution was carried in standard black 24-well cell culture plates and the extent of cell viability was measured by Microplate Fluorescence Reader (BioTek FLx800, bad Friedrichshall, Germany) with an extinction wave length of 480nm and an emission wave length of $520 \mathrm{~nm}$.

Tunel assay: For the apoptosis TUNEL-Assay, the three cell lines (HUVEC, HOB, NHDF, $\left.5 \times 10^{4}\right)$ in EBM, DMEM and SCGM medium were seeded to 6 well plates. After 24 hours, all cell lines were incubated with $50 \mu \mathrm{mol}$ bisphosphonates (clodronate, ibandronate, pamidronate and zoledronate) including a negative control group for 72 hours. Cells were solved by Trypsin-EDTA and centrifuged onto cover slips by $2000 \mathrm{rpm}$ for 5 minutes. Then cells were fixed with $3 \%$ paraformaldehyd for 10 minutes at room temperature (RT), permeabilized with $0.1 \%$ Triton $\mathrm{X}-100,0.1 \%$ sodium citrate for 2 minutes on ice, washed twice with PBS, $\mathrm{pH}$ 7.4, and incubated for one hour at $37^{\circ} \mathrm{C}$ in the dark with a TUNEL reaction mixture (Boehringer, Ingelheim, Germany), for in situ detection of cell death. After washing twice with PBS, pH 7.4, cells were incubated at RT with the Hoechst solution for 5 minutes. All Hoechst-positive nuclei as well as TUNEL-positive nuclei were visualized using a Zeiss Axioplan fluorescence microscope. Apoptosis was expressed as a percent of fragmented Hoechst-positive nuclei versus total Hoechst-positive nuclei, and as a percent of TUNELpositive nuclei versus total Hoechst-positive nuclei and are shown as fold increase versus control.

Migration Assay (Boyden-Chamber): To examine the effects of bisphosphonates on the migration ability of HUVEC, osteoblasts and fibroblasts, a 24-well Boyden Chamber Assay system (ThinCert ${ }^{\mathrm{TM}}$, pore size $8 \mu \mathrm{m}$ translucent, Greiner BioOne, Essen, Germany) with a 
1

2

3

4

5

6

7

8

9

pore size of $8 \mu \mathrm{m}$ was used according to the manual (Greiner BioOne, Essen, Germany). All cell lines were incubated for 72 hours with different bisphosphonates and $50 \mu \mathrm{mol}$. Cells were harvested, washed twice in PBS and re-suspended in cell culture medium at a final concentration of $10^{6} \mathrm{ml}^{-1}$. After 24 hours, the cells were stained with Calcein-AM fluorescent dye (invitrogen ${ }^{\mathrm{TM}}$, Eugene, Oregon, USA). Thereafter, the culture medium was removed from the inserts, and the inserts were transferred to the wells of a new 24-well plate containing 500 $\mu 1$ Trypsin-EDTA per well. This plate was incubated for 10 minutes in a cell culture incubator at $37^{\circ} \mathrm{C}$ and $5 \% \mathrm{CO}_{2}$. The inserts were removed, and $200 \mu 1$ of the TrypsinEDTA solution, now containing the detached migratory cells, was transferred from each well of the 24 well-plate to a well of a flat-bottom black 24-well plate. For quantification of cell migration, we used a Microplate Fluorescence Reader (BioTek FLx800, Bad Friedrichshall, Germany) with an extinction of $480 \mathrm{~nm}$ and emission of $520 \mathrm{~nm}$. For each cell line and each bisphosphonate the experiments were conducted 12 times.

Statistical analysis: The hypothesis was that incubation of bisphosphonates with varying potencies has a distinct effect on cell viability, cell migration ability and apoptosis of osteoblasts, fibroblasts and endothelial cells. As a control, non-incubated cells were used. Continuous variables are expressed as mean $+/$ - standard deviation. Comparisons between groups were analysed by ANOVA (post hoc test: Tukey) for experiments with more than two subgroups (SPSS version 17.0). P values $<0.05$ were considered statistically significant. 
Results

Calcein viability-assay (figure 1 a-c):

Osteoblasts: At lower concentrations $(5-50 \mu \mathrm{mol})$, the impact of zoledronate on osteoblasts was the strongest compared to the other bisphosphonates, and was significant compared to all bisphosphonates except for clodronate, which depended on concentration. At $5 \mu$ mol, only zoledronate had a significant reduction on cell viability compared to the control $(\mathrm{p}=0.006)$. Osteoblasts were affected by clodronate, which turned out to be significant compared to the control at $100 \mu \mathrm{mol}(\mathrm{p}=0.036)$. There were no further significant differences between pamidronate and zoledronate, and there were no differences at any concentration between ibandronate and clodronate.

Fibroblasts: There was no significant difference at $5 \mu \mathrm{mol}$ between the groups. At $50 \mu \mathrm{mol}$, the differences between the control and all the other bisphosphonates ( $p=0.002$ up to 0.037 ) were significant. From this concentration level and higher, the difference between clodronate and all the other bisphosphonates were significant. The differences between the nitrogen containing bisphosphonates were significant as of $200 \mu \mathrm{mol}$, with a significant difference between pamidronate and ibandronate $(\mathrm{p}<0.001)$, and pamidronate and zoledronate $(\mathrm{p}=0.03)$. At $500 \mu \mathrm{mol}$ there is no longer a difference between pamidronate and zoledronate, but a significant difference between ibandronate and clodronate $(\mathrm{p}<0.001)$, and ibandronate and pamidronate $(\mathrm{p}=0.008)$ was found.

HUVEC: There were no significant differences at $5 \mu \mathrm{mol}$. At $200 \mu \mathrm{mol}$, clodronate has a significant impact on the cells $(\mathrm{p}=0.047)$. All other bisphosphonates turned out to have a significant impact at $50 \mu \mathrm{mol}(\mathrm{p}<0.001)$. The differences between zoledronate and all the other bisphosphonates was significant as well $(\mathrm{p}<0.001)$. At a concentration of $100 \mu \mathrm{mol}$, the difference of the impact of zoledronate and pamidronate was no longer significant.

TUNEL-Assay (figure 2): 
Osteoblasts: Zoledronate and pamidronate had the greatest impact but there was no significant difference between these two bisphosphonates. The effect of ibandronate was significantly weaker $(\mathrm{p}<0.001$ compared to zoledronate, and $\mathrm{p}=0.006$ compared to pamidronate). There was no significant difference of clodronate compared to the control, and no significant difference compared to ibandronate.

Fibroblasts: All differences between the respective bisphosphonates were statistically significant ( $\mathrm{p}$ between $\mathrm{p}<0.001$ and 0.007 ). Zoledronate had the strongest impact, followed by pamidronate, ibandronate and clodronate. The level of apoptosis was nearly $77 \%$ for zoledronate and $61 \%$ for pamidronate.

HUVEC: Pamidronate and zoledronate had the strongest effect $(\mathrm{p}<0.001)$ but there was no significant difference between these two bisphosphonates $(\mathrm{p}=0.522)$. Ibandronate and clodronate had a considerably smaller but nevertheless significant effect on the apoptosis rate $(\mathrm{p}<0.001$ for ibandronate and $\mathrm{p}=0.005$ for clodronate). The impact difference between ibandronate and clodronate was not significant $(\mathrm{p}=0.351)$.

Boyden Migration Assay (figure 3):

For each cell type, the ANOVAs conducted showed significant differences among the experimental groups and control group. Each ANOVA yielded a p-value $<0.001$.

Osteoblasts: Only the nitrogen containing bisphosphonates inhibited the migration ability of osteoblasts. There was no significant difference between zoledronate, pamidronate and ibandronate.

Fibroblasts: All bisphosphonates inhibited the migration ability, save clodronate. The strongest effect was measured for pamidronate $(\mathrm{p}<0.001$ compared to all other bisphosphonates). There was no significant difference between zoledronate and ibandronate. HUVEC: All bisphosphonates inhibited the migration ability of HUVEC. Zoledronate and pamidronate had the strongest effect, but there was no significant difference between these 
two bisphosphonates. There were similar results for the significantly less potent clodronate and ibandronate with no significant difference between them. 


\section{Discussion}

In addition to reduced bone remodelling several theories regarding the aetiology of bisphosphonate osteonecrosis of the jaw are being discussed in literature (Allen and Burr, 2009). The range of aetiological possibilities has been broadened with the realization that not only osteoclasts, but rather several cell types are affected by bisphosphonates, as shown in this study.

Clodronate, representing the non-nitrogen containing bisphosphonates, has nearly no impact on the apoptosis rate of the investigated cell lines. The effect of clodronate on cell viability of HUVEC fibroblasts and osteoblasts was not as large compared to the other bisphosphonates, yet still yielded significant results in higher concentrations. As well, the effect on cell migration was marginal and statistically significant only for HUVEC, so that the over all effect of clodronate is minimal, which could explain the rarity of BP-ONJ in patients receiving clodronate. Among the nitrogen containing bisphosphonates represented by ibandronate, pamidronate and zoledronate, pamidronate and zoledronate had the greatest effect on all cell types and functions. One exception is the effect of zoledronate and Pamidronat on the migration rate of fibroblasts with a way higher effect of pamidronat. The apoptosis rate in cells incubated with ibandronate is either as high as the cells incubated with clodronate (osteoblasts, HUVEC) or is little higher (fibroblasts). A similar results was obtained for the cell viability, with an effect just as high as clodronate for osteoblasts. The effect on fibroblasts and HUVEC was stronger, but not as strong as the effect of zoledronate and pamidronate. These last two bisphosphonates had the greatest impact on the apoptosis rate, the cell viability and the migration ability of all cell lines with only a few exceptions.

Similar results regarding migration ability and cell viability have previously been described (Walter et al., 2009). A migration assay was performed with a scratch wound assay, and results showed that clodronte had had the weakest effect on all cell types, which is similar to the present study. The cell migration was most strongly inhibited by zoledronate and 
pamidronate, with the exception of fibroblast cell migration of where ibandronat had a greater effect than zoledronate. A similar effect is seen in the present study with the greatest effect of pamidronate on fibroblast cell migration. The cell viability test in the previously published study (Walter et al., 2009) conducted with the MTT-test clodronate evaluated the weakest effect on all tested cell types as well. Among the nitrogen containing bisphosphonates, pamidronate and zoledronate had a greater effect on the cell viability compared to ibandronate. The cell viability measured with the calcein assay seems to be higher compared to the ones evaluated with the MTT-test. This is well in accordance with the underlying test methods, as MTT is a metabolism test and therefore might be more sensitive than calcein staining alone, It should however be noted, that in these in vitro experiments for all cell types and functions tested, the influence of the different bisphosphonates is reproducible. This is even of more significance as the effect ranking of the bisphosphonates is also nearly the same in these experiements.

This in vitro study verified an impact on osteoblasts, fibroblasts and HUVEC thus supporting the idea of a multifactor pathology of BP-ONJ. It supports the clinical theory of damage to osteogenic and blood vessel cells and soft tissue repair.

These results should be verified in an animal model and might be verified in specimens from patients with BP-ONJ.

The distribution of bisphosphonates in patients with BP-ONJ is reflected by this study's results. Within the natural limitations of in vitro studies, these data support the theory that bisphosphonates influence soft tissue cells such as vessel cells and fibroblasts, in addition to osteoblasts. Although the half-life of bisphosphonates can be more than ten years (Wang et al., 2007), the finding that soft tissue cells are affected by bisphosphonates could indicate that interruption of bisphosphonate treatment to promote better wound healing in the oral cavity may be reasonable.
Deleted: which may indicate some variability is due to the test procedure

Deleted: However,

Deleted: This study verified an impact on osteoblasts, fibroblasts and HUVEC thus supporting the idea of a multifactor pathology of BP-ONJ. 


\begin{abstract}
Acknowledgement:
There was no funding for this study. Christian Walter and Bilal Al-Nawas got speecher's fees from Roche, Christian Walter received funding from Novartis for a different study.
\end{abstract}


1. Allen MR and Burr DB (2008). Mandible matrix necrosis in beagle dogs after 3 years of daily oral bisphosphonate treatment. J Oral Maxillofac Surg 66: 987-994

2. Allen MR and Burr DB (2009). The pathogenesis of bisphosphonate-related osteonecrosis of the jaw: so many hypotheses, so few data. J Oral Maxillofac Surg 67: 61-70 3. Bassett CA, Donath A, Macagno F, Preisig R, Fleisch H and Francis MD (1969). Diphosphonates in the treatment of myositis ossificans. Lancet 2: 845

4. Chen T, Berenson J, Vescio R, Swift R, Gilchick A, Goodin S, LoRusso P, Ma P, Ravera C, Deckert F, Schran H, Seaman J and Skerjanec A (2002). Pharmacokinetics and pharmacodynamics of zoledronic acid in cancer patients with bone metastases. J Clin Pharmacol 42: 1228-1236

5. Diel IJ, Bergner R and Grotz KA (2007). Adverse effects of bisphosphonates: current issues. J Support Oncol 5: 475-482

6. Frith JC, Monkkonen J, Blackburn GM, Russell RG and Rogers MJ (1997). Clodronate and liposome-encapsulated clodronate are metabolized to a toxic ATP analog, adenosine 5'-(beta, gamma-dichloromethylene) triphosphate, by mammalian cells in vitro. $J$ Bone Miner Res 12: 1358-1367

7. Green JR and Clezardin P (2002). Mechanisms of bisphosphonate effects on osteoclasts, tumor cell growth, and metastasis. Am J Clin Oncol 25: S3-9

8. Landesberg R, Cozin M, Cremers S, Woo V, Kousteni S, Sinha S, Garrett-Sinha L and Raghavan S (2008). Inhibition of oral mucosal cell wound healing by bisphosphonates. J Oral Maxillofac Surg 66: 839-847

9. Mashiba T, Mori S, Burr DB, Komatsubara S, Cao Y, Manabe T and Norimatsu H (2005). The effects of suppressed bone remodeling by bisphosphonates on microdamage accumulation and degree of mineralization in the cortical bone of dog rib. J Bone Miner Metab 23 Suppl: $36-42$

10. Montazeri AH, Erskine JG and McQuaker IG (2007). Oral sodium clodronate induced osteonecrosis of the jaw in a patient with myeloma. Eur J Haematol 79: 69-71

11. Polizzotto MN, Cousins V and Schwarer AP (2006). Bisphosphonate-associated osteonecrosis of the auditory canal. Br J Haematol 132: 114

12. Reid IR, Bolland MJ and Grey AB (2007). Is bisphosphonate-associated osteonecrosis of the jaw caused by soft tissue toxicity? Bone 41: 318-320

13. Rogers MJ, Gordon S, Benford HL, Coxon FP, Luckman SP, Monkkonen J and Frith JC (2000). Cellular and molecular mechanisms of action of bisphosphonates. Cancer $\mathbf{8 8}$ : 2961-2978

14. Rubegni P and Fimiani M (2006). Images in clinical medicine. Bisphosphonateassociated contact stomatitis. $N$ Engl J Med 355: e25

15. Ruggiero SL, Dodson TB, Assael LA, Landesberg R, Marx RE and Mehrotra B (2009). American Association of Oral and Maxillofacial Surgeons position paper on bisphosphonate-related osteonecrosis of the jaws--2009 update. J Oral Maxillofac Surg 67: 212

16. Santini D, Vespasiani Gentilucci U, Vincenzi B, Picardi A, Vasaturo F, La Cesa A, Onori N, Scarpa S and Tonini G (2003). The antineoplastic role of bisphosphonates: from basic research to clinical evidence. Ann Oncol 14: 1468-1476

17. Walter C, Al-Nawas B, Grotz KA, Thomas C, Thuroff JW, Zinser V, Gamm H, Beck J and Wagner W (2008). Prevalence and risk factors of bisphosphonate-associated osteonecrosis of the jaw in prostate cancer patients with advanced disease treated with zoledronate. Eur Urol 54: 1066-1072 
1

18. Walter C, Klein MO, Pabst A, Al-Nawas B, Duschner H and Ziebart T (2009). Influence of bisphosphonates on endothelial cells, fibroblasts, and osteogenic cells. Clin Oral Investig

19. Wang EP, Kaban LB, Strewler GJ, Raje N and Troulis MJ (2007). Incidence of osteonecrosis of the jaw in patients with multiple myeloma and breast or prostate cancer on intravenous bisphosphonate therapy. J Oral Maxillofac Surg 65: 1328-1331 
Legends:

Figure 1: $\quad$ Cell viability test for osteogenic cells (a), fibroblasts (b) and human umbilicord vein endothelial cells (c) influenced by clodronate, ibandronate, pamidronate and zoledronate at different concentrations compared to a control set to $100 \%$. Asterixs indicate concentrations that are significantly different from control.

Figure 2: Tunel assay for osteogenic cells, fibroblasts and human umbilicord vein endothelial cells influenced by $50 \mu \mathrm{mol}$ clodronate, ibandronate, pamidronate or zoledronate compared to a control without bisphosphonates. The black bar in the middle of each box represents the median. The box includes all values between the $25^{\text {th }}$ and $75^{\text {th }}$ percentile. Whiskers indicate values still within 1.5 interquartile range (IQR). Outliers within $3 \mathrm{IQR}$ are represented as circles, outliers over $3 \mathrm{IQR}$ are represented as asterix.

Figure 3: $\quad$ Boyden chamber migration assay for osteogenic cells, fibroblasts and human umbilicord vein endothelial cells influenced by $50 \mu \mathrm{mol}$ clodronate, ibandronate, pamidronate or zoledronate compared to a control without bisphosphonates. The black bar in the middle of each box represents the median. The box includes all values between the $25^{\text {th }}$ and $75^{\text {th }}$ percentile. Whiskers indicate values still within 1.5 interquartile range (IQR). Outliers within 3 IQR are represented as circles. 

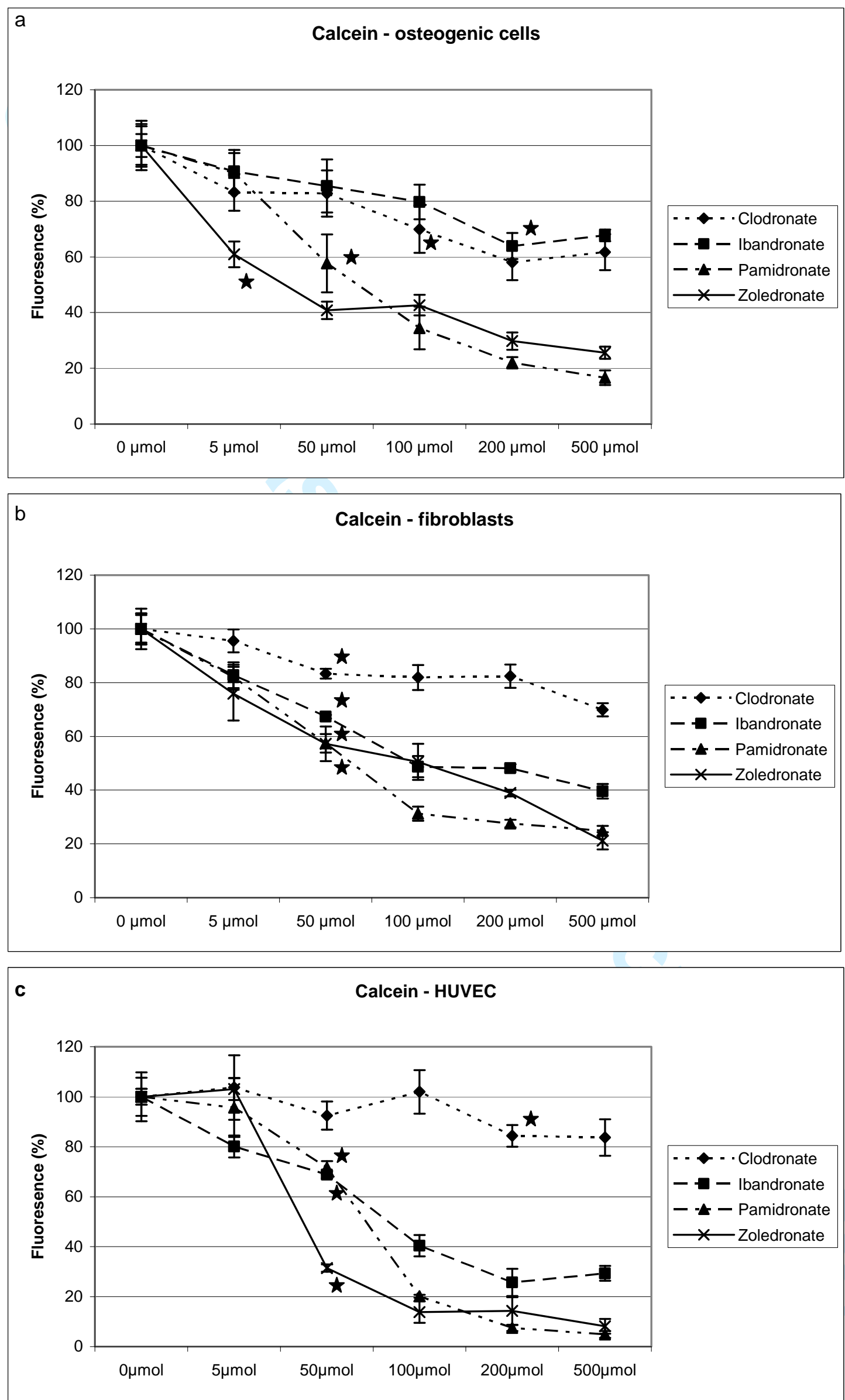


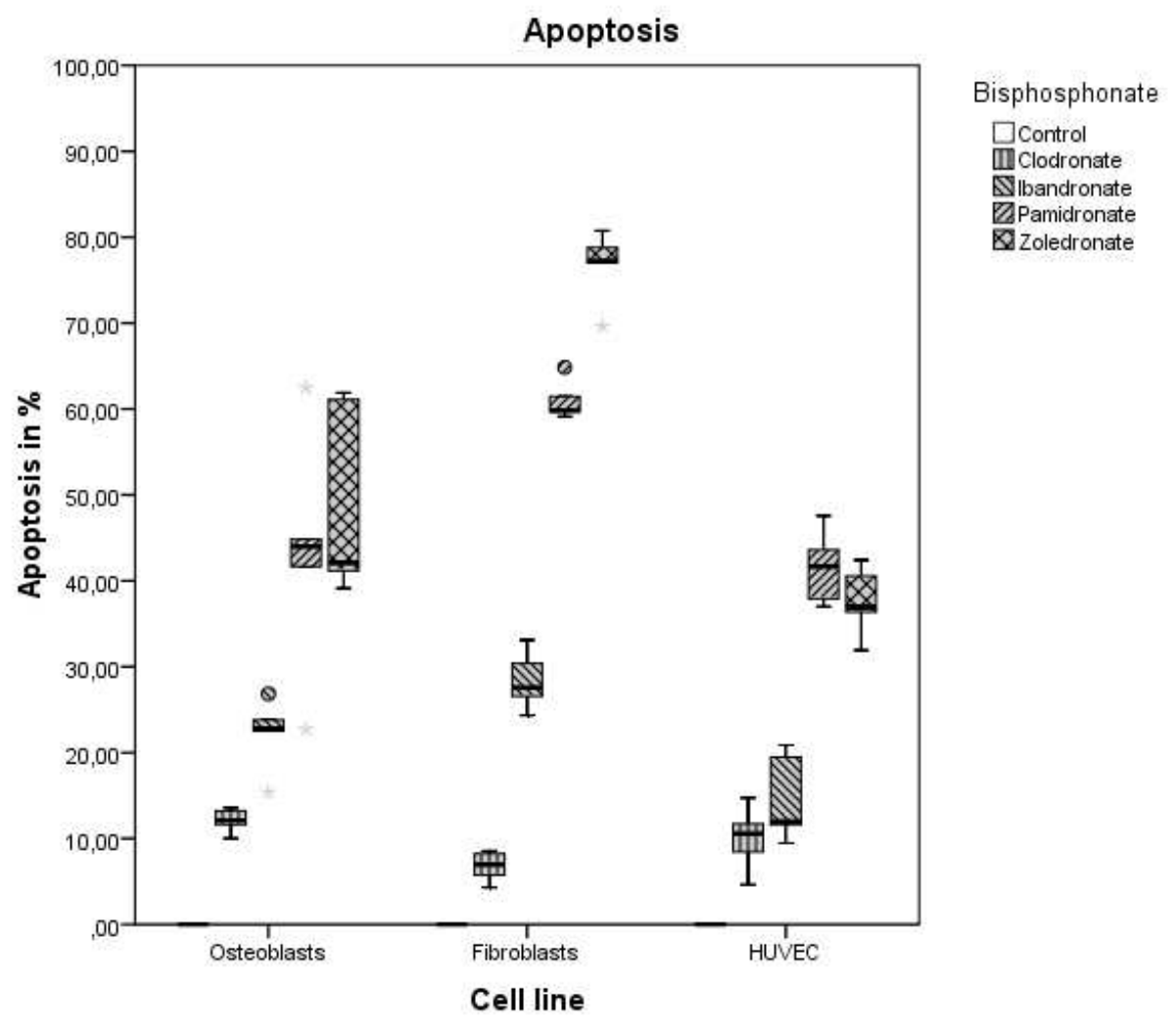

Tunel assay for osteogenic cells, fibroblasts and human umbilicord vein endothelial cells influenced by $50 \mu \mathrm{mol}$ clodronate, ibandronate, pamidronate or zoledronate compared to a control without bisphosphonates. The black bar in the middle of each box represents the median. The box includes all values between the 25th and 75th percentile. Whiskers indicate values still within 1.5 interquartile range (IQR). Outliers within 3 IQR are represented as circles, outliers over 3 IQR are represented as asterix. 


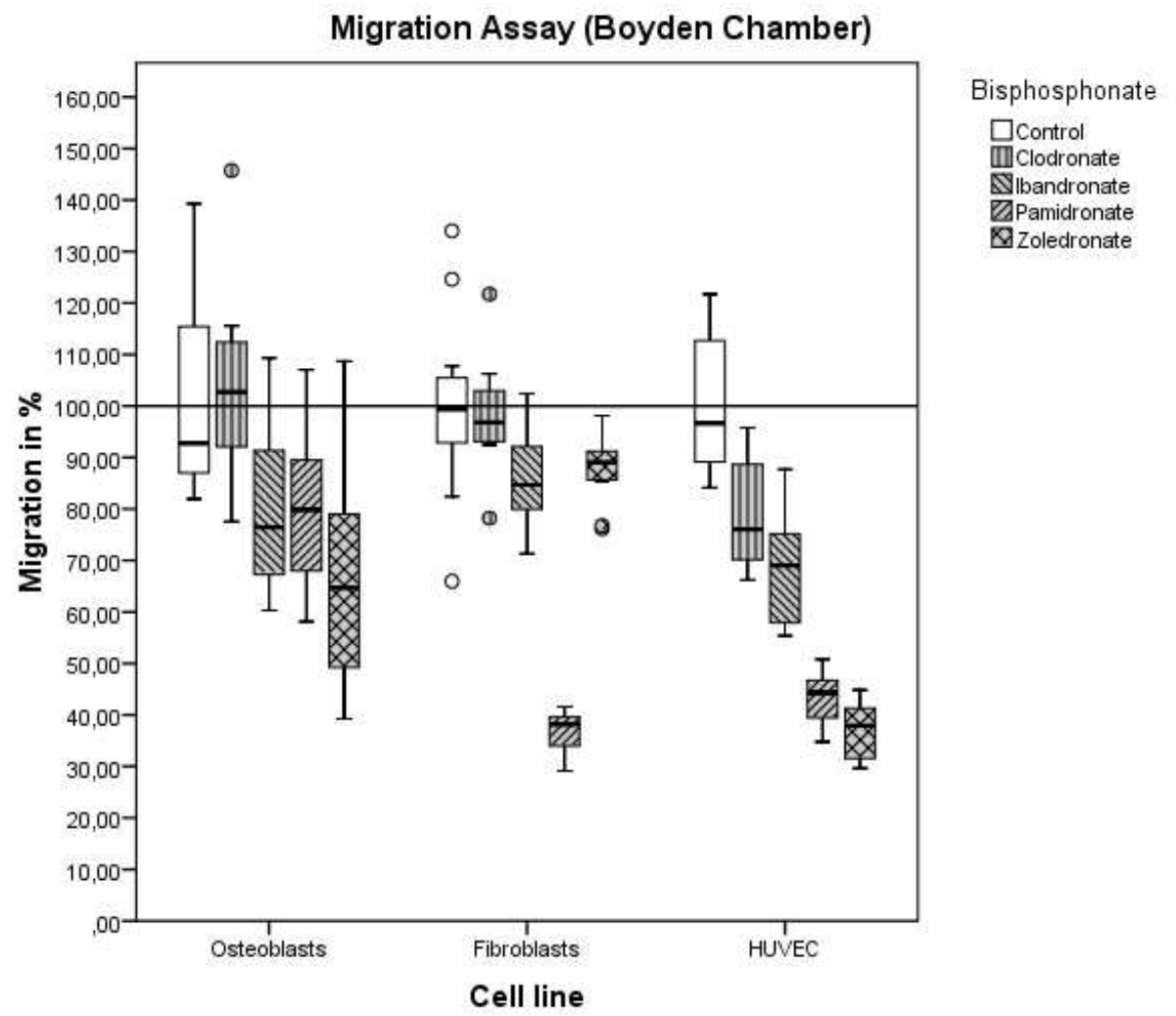

Boyden chamber migration assay for osteogenic cells, fibroblasts and human umbilicord vein endothelial cells influenced by $50 \mu \mathrm{mol}$ clodronate, ibandronate, pamidronate or zoledronate compared to a control without bisphosphonates. The black bar in the middle of each box represents the median. The box includes all values between the 25th and 75th percentile. Whiskers indicate values still within 1.5 interquartile range (IQR). Outliers within 3 IQR are represented as circles. 